\title{
Práticas Educativas Inclusivas na Educação Infantil: uma Revisáo INTEGRATIVA DE LITERATURA ${ }^{1,2}$

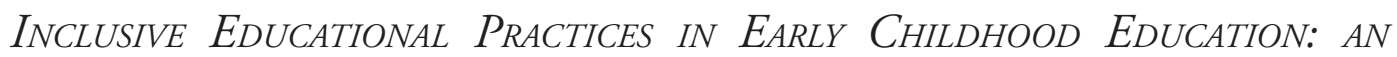 INTEGRATIVE REVIEW OF THE LITERATURE
}

\author{
Amanda Gabriele Cruz CARVALHO 3 \\ Andréia SCHMIDT ${ }^{4}$
}

\begin{abstract}
RESUMO: A Educação Inclusiva preconiza equidade de oportunidades para os alunos em todas as etapas da educação, inclusive na Educaçấo Infantil. O conhecimento e a implementaçâo de práticas com evidências de eficácia no cotidiano escolar podem favorecer a concretização dos princípios da Educação Inclusiva. Assim sendo, o objetivo desta revisão foi analisar, na literatura científica, práticas educativas inclusivas de dimensão processual para a Educação Infantil que apresentam indícios de efetividade e/ou eficácia na última década. Foram consultadas as bases da Biblioteca Eletrônica Científica Online (SciELO), da PsycINFO, do Education Resources Information Center (ERIC) e da Web of Science (WoS) entre 2009 e 2019, em busca de pesquisas empíricas, realizadas no contexto escolar, que descrevessem intervençóes diretas com grupos de alunos e que envolvessem crianças público-alvo da Educação Especial. Dos 274 artigos extraídos, foram analisados nove após análise dos critérios de elegibilidade. Os artigos foram classificados quanto ao nível de evidência. Em seguida, as práticas com indícios de efetividade descritas nos artigos foram categorizadas como transversais, antecedentes às atividades, posteriores e realizadas durante as atividades $(\mathrm{n}=23)$. Apesar de as práticas analisadas parecerem relativamente simples de serem implementadas no cotidiano escolar, seu conjunto mostra a importância do planejamento, da organização e da condução das atividades escolares, de forma a promover oportunidades concretas para que crianças com alguma deficiência possam desenvolver plenamente seu potencial.
\end{abstract}

PALAVRAS-CHAVE: Práticas educativas. Relação professor-aluno. Educaçấo Inclusiva. Educação Infantil.

\begin{abstract}
Inclusive Education advocates equity of opportunity for all students in all stages of education, including Early Childhood Education. The knowledge and implementation of practices with evidence of efficacy in everyday school life can promote the realization of the principles of Inclusive Education. Thus, the objective of this review was to analyze, in the scientific literature, inclusive educational practices within the process dimension for Early Childhood Education that present evidence of effectiveness and/or efficacy in the last decade. The Scientific Electronic Library Online (SciELO), PsycINFO, Education Resources Information Center (ERIC) e Web of Science (WoS) were consulted between 2009 and 2019, in search of empirical research, carried out in the school context, describing direct interventions with groups of students and involving the target children of Special Education. From the 274 articles extracted, nine were analyzed after analysis of eligibility criteria. The articles were classified in terms of level of evidence. Next, the practices with evidence of effectiveness described in the articles were categorized as transversal, antecedent to activities, posterior and performed during the activities $(n=23)$. Although the analyzed practices seem relatively simple to be implemented in school routines, as a whole they show the importance of planning, organizing and conducting school activities, in order to promote concrete opportunities for children with any disability to fully develop their potential.
\end{abstract}

KEYWORDS: Educational Practices. Teacher-student interactions. Inclusive Education. Early Childhood Education.

\footnotetext{
${ }^{1}$ https://doi.org/10.1590/1980-54702021v27e0231

${ }^{2}$ Esta pesquisa faz parte do programa científico do Instituto Nacional de Ciência e Tecnologia sobre Comportamento, Cognição e Ensino (INCT-ECCE), financiado pelo Conselho Nacional de Pesquisa (CNPq) - Processo 465686/2014-1, e pela Fundação de Amparo à Pesquisa do Estado de São Paulo (FAPESP) - Processo 2014/50909-8.

${ }^{3}$ Pesquisadora autônoma. Graduanda do curso de Psicologia da Faculdade de Filosofia, Ciências e Letras de Ribeirão Preto -Universidade de São Paulo (USP). Ribeirão Preto/São Paulo/Brasil. E-mail: gccarvalho@usp.br. ORCID: https://orcid.org/0000-0002-9481-8297

${ }^{4}$ Docente do Departamento de Psicologia da Faculdade de Filosofia, Ciências e Letras de Ribeirão Preto -Universidade de São Paulo (USP). Ribeirão Preto/São Paulo/Brasil. E-mail: aschmidt@ffclrp.usp.br. ORCID: https://orcid.org/0000-0002-8836-6618
} 


\section{INTRODUÇÁo}

No Brasil, a Educação Infantil constitui-se como primeira etapa da Educação Básica e é um direito garantido por Lei a todas as crianças de 0 a 5 anos (Resolução no 4, de 13 de julho de 2010). Assim como todas as demais etapas de ensino, a Educação Infantil também deve seguir os princípios de uma Educação Inclusiva. Segundo a definição da Secretaria de Educação Básica, por meio da Política Nacional de Educação Especial na Perspectiva da Educação Inclusiva - PNEEPEI (2008), a Educação Inclusiva é uma proposta de ensino fundamentada nos direitos humanos e na equidade de oportunidades, na qual o sistema educacional deve organizar-se para garantir que todos os alunos aprendam juntos e tenham suas especificidades atendidas.

Historicamente, a Educação Especial era entendida como uma modalidade paralela ao ensino regular ou, quando estendida para classes regulares, resumia-se ao mero acesso do aluno com deficiência a um espaço comum (PNEEPEI, 2008). Com a Resolução $\mathrm{n}^{\circ}$ 4, de 13 de julho de 2010, a Educação Especial passou a ser parte integrante, não substitutiva, do ensino regular e uma modalidade transversal a todos os níveis, a todas as etapas e as modalidades de ensino, contando com o Atendimento Educacional Especializado (AEE) para orientar as adaptaçóes pedagógicas adequadas para cada caso. Essa mudança refletiu nos documentos oficiais sobre o sistema regular de ensino.

A Base Nacional Comum Curricular - BNCC (2017) é o documento que norteia os sistemas público e privado de educação na elaboração de seus currículos, desde a Educação Infantil até o Ensino Médio. Esse documento estabelece os conhecimentos, as habilidades e as competências (as aprendizagens essenciais) a serem desenvolvidos pelos estudantes em todos esses níveis de ensino. $\mathrm{O}$ documento reafirma o compromisso do ensino brasileiro com a Educação Inclusiva, atribuindo às redes de ensino e às instituiçóes escolares a tarefa de elaborar currículos que contextualizem os conteúdos dos componentes curriculares, indiquem formas de organização interdisciplinar desses componentes, selecionem estratégias e metodologias diversificadas, construam formas de avaliação formativa, dentre outras. A BNCC (2017), portanto, delega a estados e a municípios a definição sobre como o ensino será conduzido nos diferentes níveis, incluindo a Educação Infantil. Por um lado, a abertura a adaptaçóes locais para abarcar especificidades institucionais e culturais faz sentido dentro de um país tão diverso como o Brasil. Por outro lado, abre margem para a ampliação das desigualdades na qualidade da educação oferecida em diferentes regióes. Nesse viés, os agentes envolvidos nos processos educacionais, e as crianças por eles atendidas, podem beneficiar-se do conhecimento sobre quais práticas são provavelmente mais capazes de concretizar os princípios de inclusão e de qualidade no cotidiano das salas de aula.

No cenário internacional, as organizações de referência para a primeira infância recomendam práticas educativas amplamente baseadas em evidências empíricas, amparadas pelos conhecimentos da área de desenvolvimento infantil e apoiadas na avaliação das especificidades de cada criança atendida, a fim de promover o máximo desenvolvimento em múltiplos domínios e diminuir as disparidades de aprendizagem entre crianças com diferentes condiçôes prévias (por exemplo, a National Association for the Education of Young Children [NAEYC], 2009). Essa abordagem à educação de todas as crianças pode ser complementada com práticas mais especializadas para promover a inclusão de alunos em situaçóes variadas de desvantagem, 
incluindo desde deficiências até problemas de comportamento, baixa renda e outras condiçôes que colocam a criança em risco de desenvolver atrasos na aprendizagem (Division for Early Childhood [DEC], 2014). O conceito de "inclusão" utilizado por essas organizaçóes, portanto, aponta para uma abrangência que ultrapassa a delimitação de público-alvo da Educação Especial (i.e. estudantes com deficiência, transtornos globais do desenvolvimento e altas habilidades/superdotação) adotada oficialmente no Brasil (PNEEPEI, 2008). Na presente revisão, foi adotada a definição internacional, uma vez que permite serem incluídas práticas voltadas a crianças ou a situaçôes que também representam um desafio à Educaçáo Inclusiva nas classes brasileiras.

A implementação de práticas educativas inclusivas baseadas em evidências é especialmente importante na Educação Infantil, pois, nesse estágio, a criança precisa ter oportunidade de desenvolver habilidades pré-acadêmicas fundamentais para o sucesso na escolarização posterior. Como verificaram Benitez et al. (2017), fragilidades no planejamento de ensino especializado para estudantes com deficiência na Educação Infantil criam grande defasagem de repertórios acadêmicos no Ensino Fundamental.

A Educação Infantil inclusiva envolve diferentes agentes, como gestores, familiares, professores e profissionais de apoio (Instituto Nacional de Estudos e Pesquisas Educacionais Anísio Teixeira [INEP], 2018). Neste estudo, foram focalizadas as açóes desempenhadas pelos professores, mais especificamente as práticas inseridas no que Ayich et al. (1999) chamam de "dimensão processual de um programa de ensino", que compreende as interaçôes entre professor e aluno, assim como os tipos de atividades propostas às crianças, e que são consideradas mais facilmente modificáveis pelo professor. Daqui em diante, tais ações serão referidas como Práticas Educativas (PEs). De fato, as decisóes e as açóes que o professor adota em tempo real em sala de aula parecem ser o preditor mais importante para o que as crianças aprendem, dado que um dos pré-requisitos para um processo de tomada de decisão efetivo é ter à disposição um repertório de PEs bem estabelecido (NAEYC, 2009).

Algumas pesquisas brasileiras exploraram a questão da preparação insuficiente dos professores de diferentes níveis educacionais sobre o conceito de "Educação Inclusiva e o trabalho em contextos inclusivos" a partir de relatos dos próprios professores. Esses estudos identificaram percepções que, algumas vezes, vão contra a própria determinação da Resolução $\mathrm{n}^{\circ}$ 4, de 2010, como a crença da necessidade de uma avaliação prévia da capacidade de acompanhar os demais alunos para determinar a possibilidade de inclusão (Teixeira et al., 2016). Os professores que reconhecem a importância da inclusão não se sentem capazes de promovê-la e declaram a necessidade de melhor formação (De Vitta et al., 2010). Esses relatos revelam uma demanda por maior acesso a conhecimentos e habilidades para a tomada de decisão em sala de aula. Nesse sentido, a sistematização de evidências, realizada por meio de revisóes de literatura, pode contribuir para melhorar a qualidade da Educação Inclusiva de duas formas: indicando para a comunidade científica questóes que precisam ser melhor investigadas e informando os profissionais e as instituiçóes de ensino sobre boas práticas a serem incorporadas nos currículos de formação do professor. Apesar da publicação de várias revisões sobre a inclusão na Educação Infantil na última década, nenhuma foca especificamente na discussão de práticas com indícios de efetividade e foi estudada empiricamente para essa faixa etária. 
Levando em consideração essa necessidade, o objetivo desta revisão foi analisar, na literatura científica, o conjunto de PEs inclusivas de dimensão processual para a Educação Infantil, implementadas em contextos escolares naturais ou que se aproximam deles, que apresentam indícios de efetividade e/ou eficácia na última década. Mais especificamente, buscou-se identificar, descrever e discutir a relevância das práticas encontradas para a atuação do professor na sala de aula em um contexto de Educação Inclusiva.

\section{Método}

Foi realizada uma revisão integrativa, de acordo com a definição de Souza et al. (2010). Dito isso, esta seção trata das bases de dados selecionadas para consulta e dos procedimentos utilizados após a extração dos artigos.

\subsection{Bases De Dados}

As bases de dados para consulta foram selecionadas a partir do critério de ter pelo menos uma base em cada uma das categorias a seguir: que representasse a produçáo científica brasileira; que abrangesse, predominantemente, pesquisas na área de Psicologia; que incluísse, principalmente, pesquisas na área da educação; que abrangesse pesquisas em diversas áreas, com revistas indexadas com bons fatores de impacto. Seguindo esses critérios, foram selecionadas as bases: Biblioteca Eletrônica Científica Online (SciELO), PsycINFO, Education Resources Information Center (ERIC) e da Web of Science (WoS).

Para a seleção dos artigos, foram utilizados os seguintes termos de busca em inglês: "special education", "preschool teachers" e "educational practices", com a exclusão de artigos que continham a palavra "parents". Também foram utilizados os seguintes termos de busca em português (especificamente na base SciELO): "educação especial”, "educação infantil" e "professores". As palavras poderiam estar em qualquer um dos campos do artigo (e.g. título ou corpo do texto). O tipo de arquivo foi limitado a artigos, publicados entre 2009 e 2019, nos idiomas inglês, espanhol e português.

Os critérios de inclusão foram: pesquisas exclusivamente empíricas; realizadas no contexto escolar, em atuaçóes exclusivamente educativas; que descrevessem intervençóes educativas diretas com grupos ou duplas de alunos e que apresentassem avaliação dos resultados em alguma variável de aprendizagem dos alunos; cujos participantes fossem crianças da Educação Infantil e que envolvessem crianças público-alvo da Educação Especial ou em risco de desenvolver atrasos em classes regulares de ensino; que envolvessem o componente da instrução direta ou indireta do aplicador da intervenção aos alunos, independentemente de ser dentro de sala de aula ou não (o contexto da intervenção poderia ser lúdico, de atividades de rotina ou em aula, desde que tivesse algum objetivo de ensino definido).

Foram excluídos os artigos que fossem teóricos ou revisão de literatura; que envolvessem PEs em instituições ou classes especiais; que elegessem como variável independente principal as características pessoais do professor implicadas em suas PEs (e.g. nível de formação, crenças de autoeficácia, idade, gênero); que fossem estudos de avaliação de um programa de 
ensino como um todo, com foco em variáveis contextuais, globais ou estruturais, conforme classificação proposta por Ayich et al. (1999).

\subsection{Procedimentos}

Após a extração de todos os artigos das bases, realizada no dia 20 de setembro de 2019, a seleção ocorreu em duas fases. Na primeira fase, de triagem, os artigos duplicados foram removidos, tanto dentro de cada base quanto entre elas. Em seguida, foi aferida a elegibilidade dos artigos com base nos critérios de inclusão e de exclusão - inicialmente, mediante leitura dos títulos e dos resumos; e, depois, no caso daqueles cuja elegibilidade não pôde ser determinada, mediante leitura na íntegra. Dúvidas quanto à elegibilidade de um artigo foram discutidas com um segundo juiz, que fez a análise dos títulos e dos resumos com base nos critérios de inclusão/exclusão. Dessas fases, resultou o conjunto de artigos selecionados. A partir da leitura completa desses artigos, os dados de interesse foram coletados e organizados utilizando-se um roteiro estruturado (adaptado de Souza et al., 2010), que contemplava os seguintes aspectos: identificação, instituição sede do estudo, tipo de publicação, características metodológicas do estudo e avaliação do rigor metodológico. A avaliação do rigor envolveu a identificação do nível de evidência de cada estudo pela caracterização do delineamento de pesquisa, de acordo com a escala de 1 a 6 proposta por Stetler et al. (1998 como citado em Souza et al., 2010), em que 1 indica a evidência de maior peso e rigor científico, a saber: a) Nível 1: evidências resultantes da meta-análise de múltiplos estudos clínicos controlados e randomizados; b) Nível 2: evidências obtidas em estudos com delineamento experimental; c) Nível 3: evidências de estudos quase-experimentais; d) Nível 4: evidências de estudos descritivos (não-experimentais) ou com abordagem qualitativa; e) Nível 5: evidências provenientes de relatos de caso ou de experiência; f) Nível 6: evidências baseadas em opinióes de especialistas.

Algumas das principais informaçóes obtidas pela coleta de dados dos artigos foram organizadas em uma tabela de levantamento, contendo a identificação do artigo, o nível de evidência, a descrição geral do objetivo, o público-alvo e as práticas investigadas e organizadas conforme a categorização elaborada. Essa categorização foi criada a partir da análise descritiva do conjunto de práticas e da identificação de padrôes que as perpassassem.

A partir dos artigos selecionados, foi elaborada uma tabela de síntese das PEs encontradas, com o intuito de agrupar as práticas que se repetiram entre os artigos e compor uma única lista de práticas com indícios de efetividade. Foram incluídas somente as práticas minimamente descritas nos procedimentos da intervenção relatadas nos artigos e implementadas em sala de aula na interação com os alunos (dimensão processual). A tabela foi organizada em práticas implementadas antes das crianças realizarem a atividade-alvo, incluindo a forma de planejamento e os comportamentos emitidos para o início da atividade (Práticas Antecedentes); práticas implementadas enquanto a atividade proposta era realizada (Práticas Durante a Atividade); práticas implementadas após emissão dos comportamentos-alvo por parte da criança - responder de forma correta, incorreta, ou não responder à solicitaçáo da atividade (Práticas Posteriores); e práticas que eram ou poderiam ser implementadas ao longo de todo o tempo de interação professor-aluno (Práticas Transversais). As PEs serão apresentadas tendo essa categorização como eixo organizador. 


\section{Resultados e discussáo}

Foram localizados, inicialmente, 274 artigos nas quatro bases pesquisadas. Após remoção dos estudos duplicados, restaram 201 estudos para análise da elegibilidade. Com a leitura dos títulos e dos resumos, restaram 18 e, por fim, a leitura na íntegra resultou em nove artigos selecionados, conforme apresentado na Figura 1.

\section{Figura 1}

Processo de extração, triagem e seleção de artigos para revisão

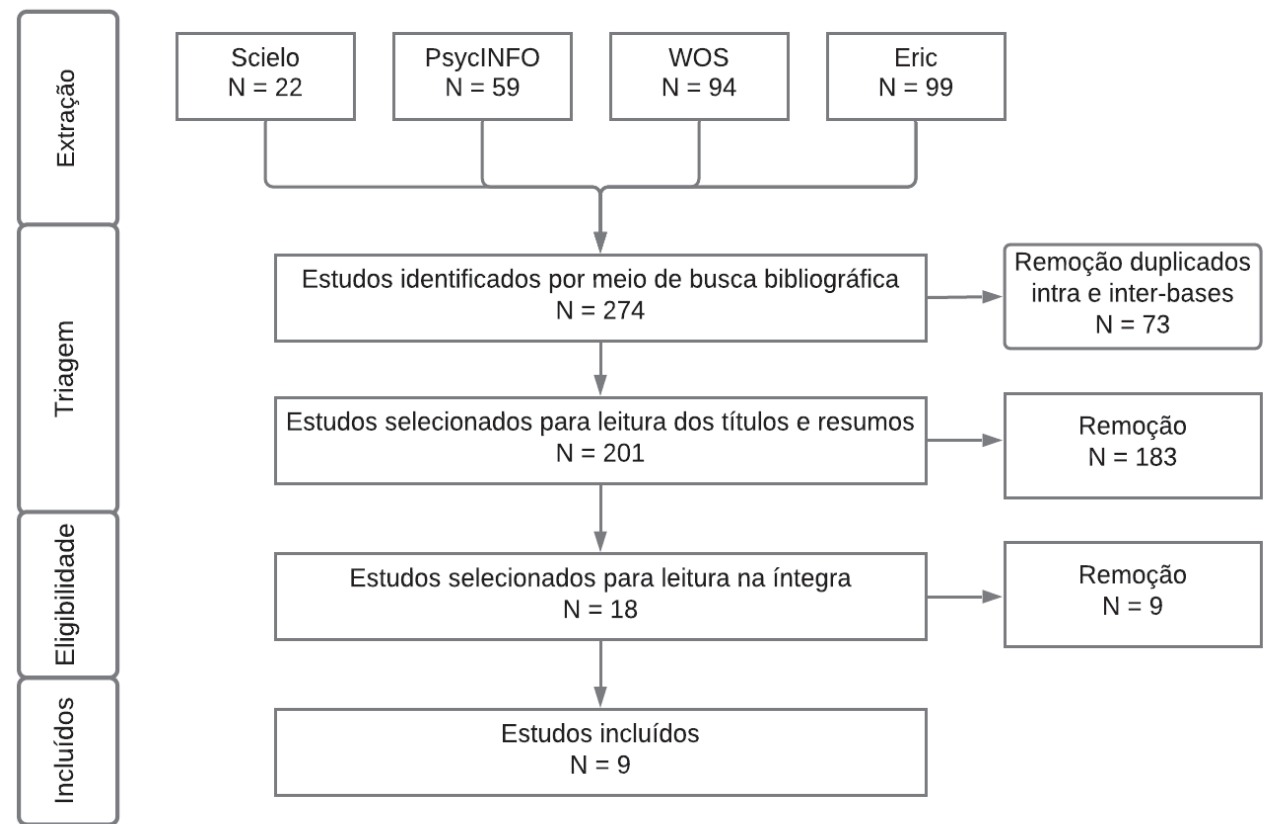

Após a análise do rigor metodológico dos artigos, foi identificado um artigo com nível 2 de evidência, que avaliou um programa abrangente no campo das competências socioemocionais para crianças com e sem problemas de comportamento, chamado Pyramid Model (Hemmeter et al., 2016). Seis artigos foram classificados com nível 3 de evidência e avaliaram intervençôes focalizadas em áreas variadas: habilidades linguísticas pré-acadêmicas (GrishamBrown et al., 2009), promoção de habilidades sociais (Stanton-Chapman et al., 2012; StantonChapman \& Brown, 2015), modelos abrangentes de intervenção para crianças com Transtorno do Espectro Autista (TEA) (Boyd et al., 2014), prevenção de problemas de comportamento (Conroy et al., 2014) e habilidades pré-acadêmicas em geral (Rakap, 2019). Por fim, foram identificados dois artigos com nível 4 de evidência. Ambos tinham como foco habilidades linguísticas pré-acadêmicas (Acosta et al., 2012; Gerde \& Powell, 2009). O critério de incluir apenas pesquisas empíricas eliminou a possibilidade de seleção de artigos de nível 1, que são aqueles de meta-análise. 
Os temas abordados com maior frequência foram as habilidades linguísticas pré-acadêmicas (3) e as habilidades sociais (3). Um dos motivos das habilidades linguísticas serem enfatizadas pode estar relacionado ao fato de constituírem a base sobre a qual a criança irá desenvolver as habilidades de compreensão necessárias em todas as áreas do currículo, incluindo o desenvolvimento da leitura e da escrita, de forma a contribuir para diminuir as lacunas de sucesso escolar entre os alunos (NAEYC, 2009). A outra principal ênfase, verificada no âmbito das habilidades sociais, reafirma que a Educação Infantil é considerada um importante espaço de convivência entre pares, e que essa experiência pode ser particularmente enriquecedora em contextos inclusivos quando se adotam práticas intencionais, orientadas a objetivos claros de aprendizagem.

O conjunto total dos artigos abordou diferentes tipos de público-alvo para inclusão, como: crianças com atrasos e/ou transtornos do desenvolvimento, transtornos emocionais/ comportamentais, atrasos linguísticos e vulnerabilidade socioeconômica. Todos os estudos demonstraram ganhos em algumas ou em todas as habilidades-alvo da intervenção, e o grau de força desses resultados foi definido em função de seus níveis de evidência. Os principais dados de identificação e de características metodológicas dos artigos são apresentados na Tabela 1 . 
Tabela 1

Descrição geral dos artigos selecionados para análise

\begin{tabular}{|c|c|c|c|c|c|c|c|c|c|}
\hline & $N$ & $m$ & $m$ & $m$ & $n$ & $n$ & $n$ & $\psi^{*}$ & 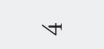 \\
\hline 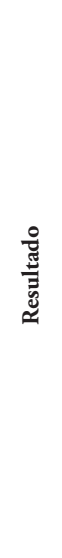 & 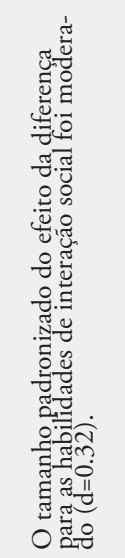 & 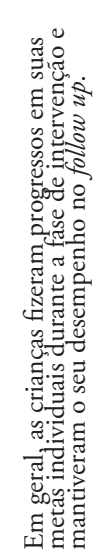 & 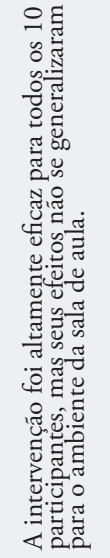 & 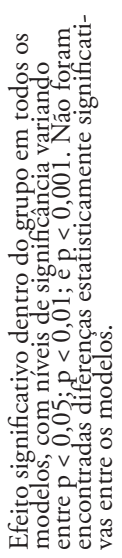 & 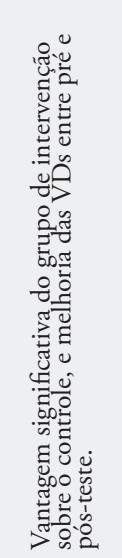 & 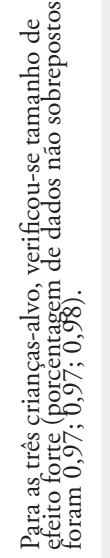 & 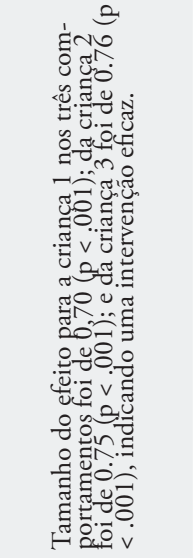 & 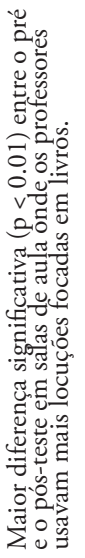 & 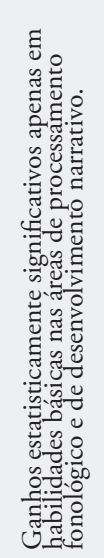 \\
\hline 这 & 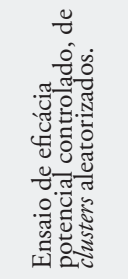 & 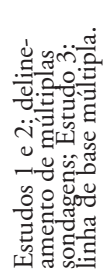 & 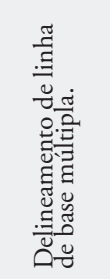 & 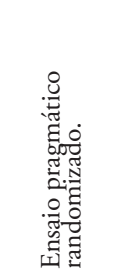 & 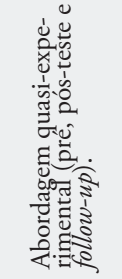 & 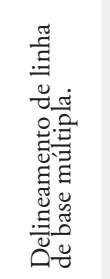 & 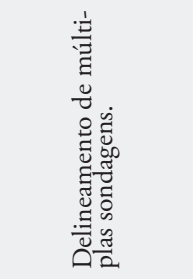 & 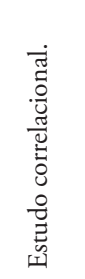 & 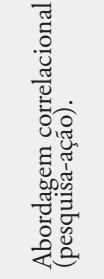 \\
\hline 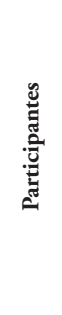 & 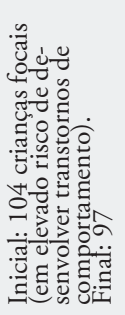 & 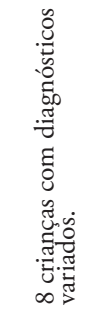 & 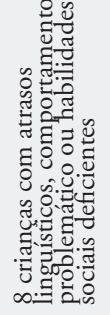 & 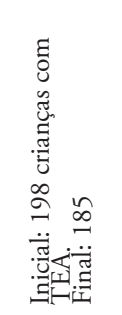 & 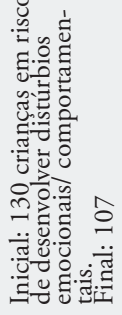 & 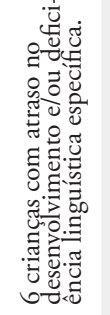 & 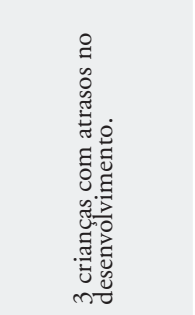 & 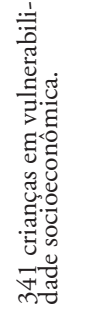 & 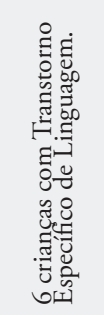 \\
\hline 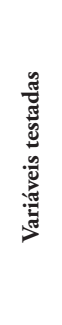 & 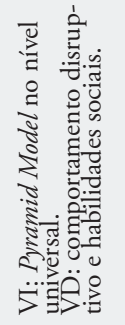 & 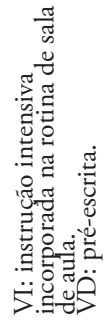 & 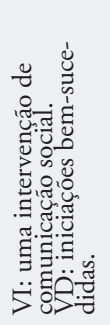 & 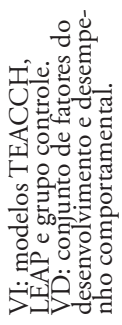 & 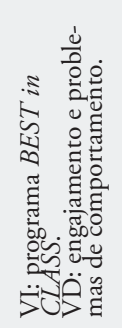 & 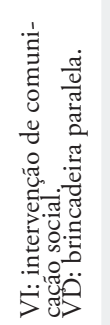 & 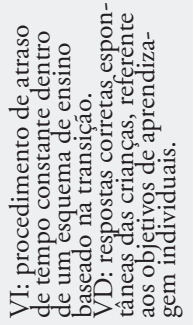 & 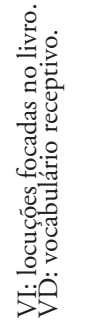 & 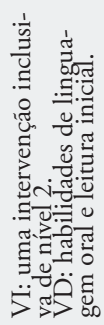 \\
\hline 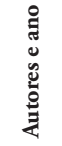 & 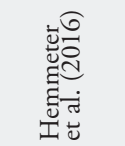 & 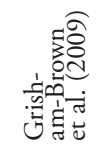 & 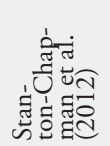 & 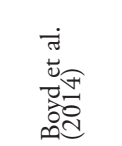 & 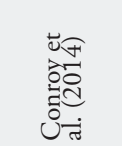 & 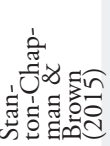 & 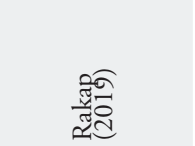 & 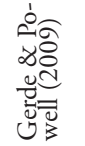 & 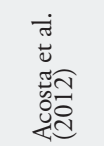 \\
\hline
\end{tabular}


A partir dos resultados dos artigos, foi elaborada uma tabela de síntese das PEs descritas nos protocolos de intervenção testados nos artigos (Tabela 2). Dos nove artigos selecionados na revisão, dois deles não apresentaram descriçóes específicas de PEs adotadas nos protocolos testados (Acosta et al., 2012; Boyd et al., 2014). Esses artigos apresentaram apenas os princípios gerais da intervenção e, por isso, a Tabela 2 não inclui nenhuma prática dessas fontes. Além disso, um artigo (Hemmeter et al., 2016) descreveu um protocolo que compreende, também, práticas não processuais, como a atuação do educador com as famílias. Nesse caso, tais práticas não foram incluídas no levantamento, sendo descrita apenas a parte processual do protocolo. A síntese dos protocolos resultou em oito práticas antecedentes, seis práticas conduzidas durante as atividades, cinco posteriores e quatro transversais. 
Tabela 2

Sintese das práticas encontradas: categorias de práticas educativas com indícios de efetividade

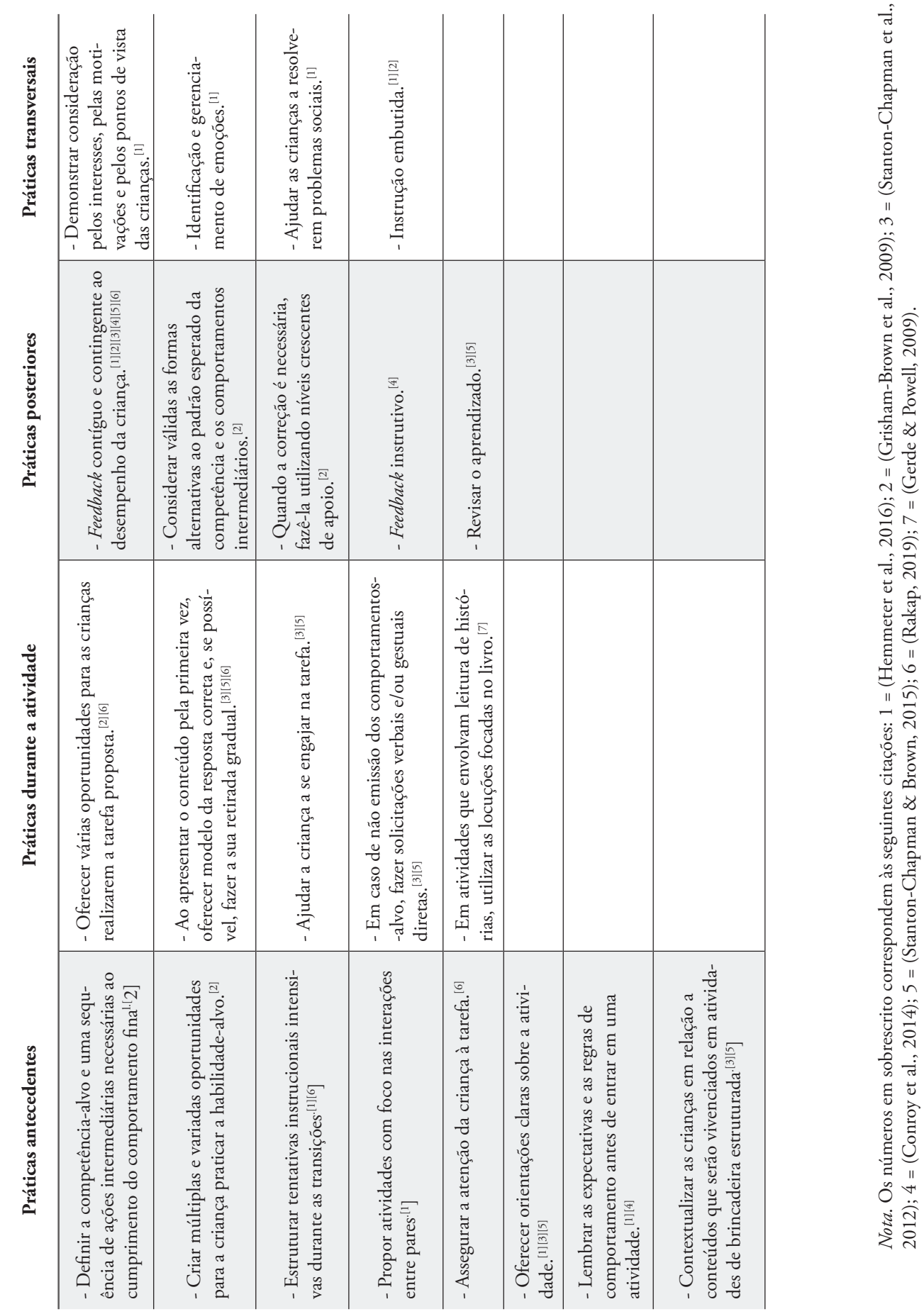




\subsection{Práticas antecedentes}

De forma geral, praticamente todos os artigos (seis deles) enfatizam a importância da organização intencional prévia da atividade e/ou da emissão de instruçôes, descriçóes ou orientaçóes claras às crianças (e.g. Conroy et al., 2014). De modo geral, é necessário que o planejamento inclua a definição das competências-alvo e uma sequência de açóes intermediárias necessárias ao cumprimento do comportamento final, para que o professor saiba quais passos devem ser atingidos pelos alunos ao longo do processo de aprendizagem do repertório que se pretende ensinar. Crianças público-alvo da Educação Especial beneficiam-se sobremaneira de ambientes ou de situaçóes que proporcionem múltiplas e variadas oportunidades para praticar a habilidade-alvo em sala de aula (Grisham-Brown et al., 2009). Criar essas oportunidades significa que o professor deve organizar um número suficiente de atividades que oportunizem à criança exercitar as etapas de um conteúdo necessárias para atingir o domínio completo de uma habilidade-alvo.

O professor também pode estruturar as transiçóes entre as atividades principais, de forma a planejar tentativas instrucionais intensivas, individualizadas e direcionadas para os objetivos de aprendizagem específicos de cada criança (Hemmeter et al., 2016; Rakap, 2019). Além de aumentar as oportunidades de aprendizagem para crianças com atrasos ou mais necessidades de apoio, as transiçóes estruturadas ocupam um tempo que, de outra maneira, seria ocioso e propício à emissão de comportamentos disruptivos (e.g. fazer barulho e tirar a concentração das crianças que ainda estão fazendo a atividade). Outra prática importante é planejar atividades que dependam da cooperação entre duas ou mais crianças para serem realizadas, como estratégia de ajudar a desenvolver competências socioemocionais em todas as crianças (Hemmeter et al., 2016). A aprendizagem desse tipo de habilidade depende da interação da criança com os seus colegas e com os adultos; situações planejadas para que essas interaçóes aconteçam podem favorecer crianças que necessitem de mais acompanhamento para o desenvolvimento desse repertório social.

Ao iniciar a atividade, é importante assegurar a atenção da criança à tarefa, por exemplo, aproximar-se dela e chamá-la pelo seu nome (Rakap, 2019); oferecer orientaçóes claras sobre qual será a atividade e como ela será realizada (Hemmeter et al., 2016; Stanton-Chapman et al., 2012; Stanton-Chapman \& Brown, 2015); e lembrar os combinados e as regras de comportamentos que serão esperados das crianças durante a atividade (Conroy et al., 2014; Hemmeter et al., 2016). Além de fornecerem um bom grau de previsibilidade para a criança sobre o que se espera dela, essas estratégias podem contribuir para prevenir e manejar o comportamento desafiador ou disruptivo das crianças.

Em atividades de brincadeira estruturada, que podem constituir contexto para o ensino de conteúdos específicos (e.g. habilidades de interação social e ampliação do vocabulário), o professor pode preparar as crianças para desempenhar os comportamentos-alvo (StantonChapman et al., 2012; Stanton-Chapman \& Brown, 2015). Antes de uma atividade que tenha como objetivo a ampliação do vocabulário das crianças, por exemplo, é necessário escolher um tema para a brincadeira entre as crianças, ensinar palavras do vocabulário alvo mostrando as figuras de seus referentes correspondentes, apresentar e explicar os papéis dos personagens, ler livro de história que seja ilustrativo do tema, decidir com as crianças quem vai desempenhar cada papel e pedir para que elas expliquem com as próprias palavras o que vão fazer duran- 
te a brincadeira. Dessa forma, o fator lúdico e interacional, enfatizado como eixo norteador para o ensino na Educação Infantil pela BNCC (2017), é associado ao princípio de prática intencional.

\subsection{Práticas durante a ATIVIdade}

Depois de preparar as crianças para as atividades principais, é importante promover oportunidades para elas desempenharem a tarefa proposta. Isso pode ser feito com a introdução de perguntas sobre a tarefa (e.g. "Que cor é essa?") e a espera de um tempo para que as crianças possam dar a resposta, por exemplo (Grisham-Brown et al., 2009; Rakap, 2019). Ao apresentar o conteúdo pela primeira vez ou diante de grande dificuldade da criança, o professor pode oferecer um modelo de resposta correta que, com o decorrer das tentativas instrucionais, pode ser retirado (Rakap, 2019; Stanton-Chapman et al., 2012; Stanton-Chapman \& Brown, 2015). O uso de modelo é vantajoso sobretudo no caso de crianças público-alvo da Educação Especial, pois garante um aprendizado inicial sem erros, o que torna mais provável o engajamento e o sucesso da criança nas tentativas instrucionais seguintes.

Quando a criança não executa a tarefa de forma espontânea, é recomendado fazer solicitações verbais e/ou gestuais diretas de forma espaçada (e.g. não mais que uma solicitação por minuto), a fim de encorajar a criança sem tornar a atividade aversiva (Stanton-Chapman et al., 2012; Stanton-Chapman \& Brown, 2015). Em alguns casos, é necessário que o professor ajude a criança a engajar-se na tarefa, direcionando-a aos materiais (se aplicável) e acompanhando-a nos primeiros passos da atividade. Isso inclui a oferta de diferentes níveis de ajuda para a realização da tarefa, que podem ser retirados ao longo do tempo à medida que a criança consegue realizar a tarefa de forma independente.

Em atividades que envolvam leitura de histórias, utilizar locuções do tipo "focadas no livro" é uma estratégia de ensino com indícios de efetividade, correlacionada com melhora significativa na linguagem receptiva, especialmente de crianças que apresentam vocabulários muito restritos em função de sua vulnerabilidade social (Gerde \& Powell, 2009). Locuções focadas no livro são expressóes verbais que o professor emite se referindo ao livro durante a sessão de leitura para um grupo de crianças, com o objetivo de estimular e manter o interesse delas. Dentre essas locuções focadas no livro, pode-se citar: fazer afirmações informativas, que incluem descriçóes gerais sobre a história ou sobre o processo de leitura e comentários que tentam conectar o livro à vida das crianças; definir palavras; fazer perguntas não retóricas fora do texto para checar algum conhecimento das crianças (e.g. “Quantas frutas ela tem?”); promover um engajamento coordenado, pedindo às crianças que repitam palavras do livro em uníssono ou encorajando-as a participar durante a leitura; pedir que as crianças façam algo relacionado ao livro (e.g. "Venha até aqui e aponte para o urso azul" ou "Qual o barulho que o cachorro fazia?").

\subsection{Práticas posteriores}

Após a execução da tarefa proposta, o professor precisa indicar às crianças se o seu desempenho está dentro do esperado ou não e ajudá-las a corrigi-lo ou ampliá-lo, caso necessário. Nesse sentido, o feedback contingente e contíguo é a prática que foi mais frequentemente 
apontada como efetiva (seis dos nove artigos). Consiste em fornecer consequência imediata e coerente ao comportamento/desempenho da criança (e.g. elogios ao comportamento correto ou correção que fornece informaçóes para comportamento/ desempenho mais próximo do esperado). É necessário que o professor deixe claro a qual comportamento específico o feedback se refere (e.g. "Que bom que você sentou perto do seu colega hoje").

É comum que algumas crianças não consigam desempenhar um determinado comportamento-alvo da mesma forma que a maioria. Nesses casos, é importante adaptar as expectativas de desempenho da competência trabalhada, considerando válidas (e fornecendo feedback positivo) as formas alternativas ao padrão esperado da competência e os comportamentos intermediários que a criança consegue desempenhar, de forma a não perder a oportunidade de desenvolver um novo repertório, mesmo que adaptado às condiçóes de cada aluno. Quando a correção é necessária, o professor pode utilizar níveis crescentes de apoio (e.g. oferecer dica, modelo, auxílio físico etc.) (Grisham-Brown et al., 2009).

Outra prática posterior é o feedback instrutivo, que consiste em reconhecer uma resposta correta ou um comportamento apropriado e fornecer informaçóes adicionais para aproveitar o contexto e ampliar o conhecimento sobre determinado assunto (Conroy et al., 2014). Por exemplo, durante a leitura de uma história, quando a criança usa de forma adequada uma nova palavra, reconhecer esse uso adequado e acrescentar informaçóes sobre essa palavra. Além disso, pode ser útil para a manutenção do aprendizado fazer uma revisão após a realização da atividade, discutindo com as crianças o desempenho delas e os conteúdos ensinados (StantonChapman et al., 2012; Stanton-Chapman \& Brown, 2015).

\subsection{Práticas transversais}

Quatro das PEs encontradas na revisão dos artigos podem ser implementadas em qualquer momento da aula. Essas práticas são voltadas para tornar as interaçôes estimulantes e responsivas, condiçóes essenciais para prevenir problemas de comportamento e promover competências socioemocionais. Para isso, é importante que o professor valorize os interesses, as motivações e os pontos de vista das crianças. O professor pode fazer isso, por exemplo, envolvendo-se em conversas de apoio e participando das brincadeiras das crianças. Ademais, o professor pode ajudar as crianças a resolverem problemas de relacionamento com colegas e a identificarem e manejarem suas emoçóes (Hemmeter et al., 2016). Essas e outras práticas tendem a ter seu efeito ampliado quando implementadas dentro da lógica da instrução embutida (embedded instruction - Grisham-Brown et al., 2009; Hemmeter et al., 2016). Isso significa distribuir o uso das estratégias de ensino orientadas aos objetivos de aprendizagem da criança ao longo das rotinas regulares do dia, de forma que se relacionem com o contexto do que a criança está fazendo (e.g. aprender a contar por meio de histórias, brincadeiras e rotinas de organização da sala de aula).

\section{Conclusóes}

Esta revisão de literatura teve como objetivo descrever um panorama e discutir as contribuiçóes do campo das pesquisas empíricas feitas na última década sobre PEs inclusivas com indícios de efetividade e/ou eficácia, que podem ser implementadas por professores na interação 
com os alunos de Educação Infantil para atingir algum objetivo de aprendizagem. A despeito de todos os artigos revisados testarem protocolos completos de intervenção, foi possível verificar PEs inclusivas específicas comuns entre eles, a serem aplicadas antes, durante e após qualquer atividade de ensino dirigida, ou ao longo de todo o período de permanência da criança na escola. As práticas destacadas enfatizam a necessidade de o professor planejar as atividades dirigidas, definindo objetivos de ensino claros e condiçóes que favoreçam à criança o desempenho da atividade dentro das suas possibilidades, de modo a valorizar seu potencial e aquilo que ela é capaz de fazer. Além disso, todos os artigos revisados enfatizam a importância de fornecer feedback claro e consistente aos alunos em relação ao seu desempenho, com vistas a valorizar a sua aprendizagem e implementar correçóes com apoio, que possam ser instrutivas e não punitivas.

Apesar de os estudos revisados terem investigado protocolos estruturados, as práticas recorrentes nesses protocolos e aqui identificadas podem ser usadas com maior flexibilidade pelo professor, de acordo com a sua avaliação e tomada de decisão das situaçóes específicas com as quais se depara. A síntese dos estudos revisados resultou em unidades de PEs que apresentam algum nível de evidência de que são eficazes no ensino de crianças com diferentes necessidades de apoio e úteis aos professores na tarefa desafiadora de desenvolver o potencial máximo de cada um de seus alunos dentro de salas de aula compostas por grande diversidade. Essas práticas, isoladamente, parecem simples e óbvias, mas talvez por isso podem ser facilmente negligenciadas no planejamento e no cotidiano dinâmico da Educação Inclusiva. Uma combinação delas, organizadas para atingir objetivos definidos de ensino, pode ser especialmente favorável para crianças com alguma condição de desvantagem. Isso é importante sobretudo quando se reconhece a necessidade de que a Educação Inclusiva para crianças pré-escolares com algum tipo de deficiência ou desvantagem deve necessariamente levar em conta objetivos funcionais para a criança, que sejam desenvolvidos nas rotinas da classe e que envolvam estratégias específicas (Brandão \& Ferreria, 2013). Implementar PEs inclusivas no ambiente de sala de aula é um dos elementos importantes para a efetivação do ensino inclusivo na Educação Infantil e não deve ser negligenciado.

Dado o significativo impacto das PEs sobre a qualidade do ensino inclusivo, adotar práticas baseadas em evidências pode ser entendido como um compromisso firmado para o desenvolvimento de todas as crianças. No entanto, esse tipo de compromisso não é claramente enfatizado por documentos oficiais, como a já citada BNCC (2017). Talvez como consequência disso, os cursos de formação de professores pouco discutem o conceito de prática baseada em evidências. De fato, alguns autores têm discutido aspectos ainda mais básicos que necessitam ser melhorados na formação do professor em diferentes níveis, como Gatti (2010), e na Educação Infantil em específico (Campos, 2018). As autoras argumentam que, embora exista a tendência de aumento no nível de formação dos professores em todas as etapas de ensino, ainda é necessário fazer frente a várias defasagens da formação e da valorização da carreira, como ofertar maior proporção de disciplinas que tratem "do que" e "do como" ensinar na prática (diminuindo, assim, a carga de disciplinas teóricas); aumentar o número de disciplinas focadas na Educação Infantil e na Educação Especial nos cursos de Licenciatura; ampliar a formação continuada e de nível superior, cujas porcentagens permanecem abaixo das metas estabelecidas no Plano Nacional de Educação (INEP, 2018); e melhorar a remuneração e os planos de carreira dos docentes da Educação Básica. Esses são apenas alguns dos grandes desafios que a Educação Infantil no Brasil ainda precisa enfrentar. 
É importante destacar que, apesar de esta revisão ter incluído quatro bases de dados com grande volume de revistas indexadas, foram encontrados relativamente poucos artigos já na extração inicial e um número ainda menor daqueles que cumpriram os critérios de inclusão. Alguns aspectos podem ser considerados para compreender esse resultado. Em princípio, esse número reduzido parece refletir a dificuldade de se produzir estudos empíricos bem fundamentados, que dependem de considerável investimento por parte dos agentes interessados pela educação, em especial de agências governamentais financiadoras. Os obstáculos podem ser ainda maiores no nível da Educação Infantil, pois persiste a ênfase em atividades de cuidado e sociabilização livre (no caso do Brasil, ver Campos, 2018; Ramos \& Salomão, 2013; Teixeira et al., 2016) e, portanto, muitas vezes é negligenciada a necessidade de produzir evidências de PEs mais efetivas.

Outrossim, como Amor et al. (2019) verificaram, existe uma forte tendência internacional para as pesquisas teóricas e descritivas no campo da inclusão na Educação Básica, acompanhadas pelas revisóes de literatura e estudos atitudinais (e.g. percepção de professores e colegas), em detrimento de avaliações de eficácia de intervenção. Esse panorama ajuda a explicar o número reduzido de artigos selecionados, pois os tipos de pesquisa encontrados com maior frequência por Amor et al. (2019) compuseram alguns dos critérios de exclusão da presente revisão. Também se deve considerar que, mesmo no âmbito das pesquisas empíricas, os investimentos podem se diluir entre as diversas áreas que podem ser foco de intervenção na Educação Inclusiva de qualidade, como gestão educacional, práticas em colaboração com a família, estratégias de formação profissional ou formação continuada dos educadores, entre outras (DEC, 2014). Tendo em vista o número relativamente pequeno de estudos empíricos sobre PEs inclusivas, pode-se considerar que este artigo avança no estado da arte para a área de Educação Especial, ao compilar resultados de pesquisas sobre PEs com alguma evidência de eficácia no ensino de crianças pré-escolares no ambiente de classes comuns. Este artigo ainda indica a necessidade de que essas práticas sejam testadas nas salas de aula brasileiras e aponta lacunas a serem melhor investigadas nas pesquisas.

O conjunto de evidências reunidas nesta revisão, no que se refere aos protocolos e aos modelos testados, apresenta importantes limitaçóes em termos de generalização para a realidade brasileira por vários motivos. As pesquisas selecionadas foram desenvolvidas nos Estados Unidos, com exceção de duas (uma realizada na Espanha e outra na Turquia). É possível argumentar que as amostras estudadas não são representativas da população brasileira, tanto em termos culturais, o que pode impactar a aceitabilidade social das intervençóes por parte dos educadores, quanto em termos socioeconômicos, que influenciam a formação profissional dos educadores, as condiçóes de sociabilização familiar da criança prévias à entrada no sistema educacional e as oportunidades de acesso à Educação Inclusiva de qualidade desde a creche. As diferenças entre países apontam, portanto, para a necessidade de realizar estudos transculturais e ampliar a produção científica nacional.

Ainda assim, essa necessidade não anula a relevância de intervenções elaboradas em outros países. As práticas aqui levantadas, a partir da análise das pesquisas revisadas, constituem-se em ações cotidianas relativamente simples e de fácil implementação na rotina das atividades dirigidas por professores. Nesse sentido, apesar das diferenças culturais e de formação entre o Brasil e os países onde as pesquisas foram realizadas, não se pode negar o potencial de 
aplicabilidade e de eficácia dessas práticas para gerar resultados importantes do ponto de vista da escola, dos alunos e da comunidade em que as crianças estiverem inseridas.

\section{REFERÊNCIAS}

Acosta, V., Moreno, A., \& Axpe, M. (2012). Inclusive action to improve oral language skills and early literacy in children with Specific Language Impairment (SLI). Revista de Educación, 359, 332-356. https://doi.org/10.4438/1988-592X-RE-2011-359-097

Amor, A. M., Hagiwara, M., Shogren, K. A., Thompson, J. R., Verdugo, M. Á., Burke, K. M., \& Aguayo, V. (2019). International perspectives and trends in research on inclusive education: A systematic review. International Journal of Inclusive Education, 23(12), 1277-1295. https://doi.org/ 10.1080/13603116.2018.1445304

Ayich, L. S., Cryer, D., Bailey Jr., D. B., \& Selz, L. (1999). Defining and assessing quality in early intervention programs for infants and toddlers with disabilities and their families: Challenges and unresolved issues. Early Education and Development, 10(1), 7-23. https://doi.org/10.1207/ s15566935eed1001_2

Base Nacional Comum Curricular: Educação é a base. (2017). Ministério da Educação. http:// basenacionalcomum.mec.gov.br/abase/\#infantil

Benitez, P., Gomes, M. L. C., Bondioli, R., \& Domeniconi, C. (2017). Mapeamento de estratégias inclusivas para estudantes com deficiência intelectual e autismo. Psicologia em Estudo, 22(1), 81-93. https://doi.org/10.4025/psicolestud.v22i1.34674

Boyd, B. A., Hume, K., McBee, M. T., Alessandri, M., Gutierrez, A., Johnson, L., Sperry, L., \& Odom, S. L. (2014). Comparative efficacy of LEAP, TEACCH and non-model-specific special education programs for preschoolers with autism spectrum disorders. Journal of Autism and Developmental Disorders, 44(2), 366-380. https://doi.org/10.1007/s10803-013-1877-9

Brandão, M. T., \& Ferreira, M. (2013). Inclusão de crianças com necessidades educativas especiais na educação infantil. Revista Brasileira de Educação Especial, 19(4), 487-502. https://doi.org/10.1590/ S1413-65382013000400002

Campos, M. M. (2018). Questóes sobre a formação de professores de educação infantil. Laplage em Revista, 4(n. esp.), 9-22. https://doi.org/10.24115/S2446-622020184especial582p.9-22

Conroy, M. A., Sutherland, K. S., Algina, J. J., Wilson, R. E., Martinez, J. R., \& Whalon, K. J. (2014). Measuring teacher implementation of the BEST in CLASS intervention program and corollary child outcomes. Journal of Emotional and Behavioral Disorders, 23(3), 144-155. https://doi. org/10.1177/1063426614532949

De Vitta, F. C. F., De Vitta, A., \& Monteiro, A. S. (2010). Percepção de professores de educação infantil sobre a inclusão da criança com deficiência. Revista Brasileira de Educação Especial, 16(3), 415-428. https://doi.org/10.1590/S1413-65382010000300007

Division for Early Childhood. (2014). DEC recommended practices in early intervention/early childhood special education 2014. http://www.dec-sped.org/recommendedpractices

Gatti, B. A. (2010). Formação de professores no Brasil: Características e problemas. Educação \& Sociedade, 31(113), 1355-1379. https://doi.org/10.1590/S0101-73302010000400016 
Gerde, H. K., \& Powell, D. R. (2009). Teacher education, book-reading practices, and children's language growth across one year of Head Start. Early Education and Development, 20(2), 211-237. https://doi.org/10.1080/10409280802595417

Grisham-Brown, J., Pretti-Frontczak, K., Hawkins, S. R., \& Winchell, B. N. (2009). Addressing early learning standards for all children within blended preschool classrooms. Topics in Early Childhood Special Education, 29(3), 131-142. https://doi.org/10.1177/0271121409333796

Hemmeter, M. L., Snyder, P. A., Fox, L., \& Algina, J. (2016). Evaluating the implementation of the Pyramid Model for promoting social-emotional competence in early childhood classrooms. Topics in Early Childhood Special Education, 36(3), 133-146. https://doi.org/10.1177/0271121416653386

Instituto Nacional de Estudos e Pesquisas Educacionais Anísio Teixeira. (2018). Relatório do $2^{\circ}$ ciclo de monitoramento das metas do Plano Nacional de Educação-2018. INEP. http://portal.inep.gov.br/ informacao-da-publicacao/-/asset_publisher/6JYIsGMAMkW1/document/id/6725829

National Association for the Education of Young Children. (2009). Developmentally Appropriate Practice in Early Childhood Programs Serving Children from Birth through Age 8. Position Statement. https:// www.naeyc.org/sites/default/files/globally-shared/downloads/PDFs/resources/position-statements/ PSDAP.pdf

Política Nacional de Educaçâo Especial na Perspectiva da Educação Inclusiva. (2008). Brasília: Secretaria de Educação Especial. http://portal.mec.gov.br/index.php?option=com_ docman\&view=download \&alias=16690-politica-nacional-de-educacao-especial-na-perspectivada-educacao-inclusiva-05122014\&Itemid $=30192$

Rakap, S. (2019). Re-visiting transition-based teaching: Impact of pre-service teacher's implementation on child outcomes. Learning and Instruction, 59, 54-64. https://doi.org/10.1016/j. learninstruc.2018.10.001

Ramos, D. D., \& Salomão, N. M. R. (2013). Desenvolvimento infantil: Concepçóes e práticas de educadoras em creches públicas. Revista Psicologia-Teoria e Prática, 15(3), 200-213.

Resolução no 4, de 13 de julho de 2010. Define Diretrizes Curriculares Nacionais Gerais para a Educação Básica. http://portal.mec.gov.br/dmdocuments/rceb004_10.pdf

Souza, M. T. de, Silva, M. D. da, \& Carvalho, R. de. (2010). Revisão integrativa: O que é e como fazer. Einstein (São Paulo), 8(1), 102-106. https://doi.org/10.1590/s1679-45082010rw1134

Stanton-Chapman, T. L., \& Brown, T. S. (2015). A strategy to increase the social interactions of 3-yearold children with disabilities in an inclusive classroom. Topics in Early Childhood Special Education, 35(1), 4-14. https://doi.org/10.1177/0271121414554210

Stanton-Chapman, T. L., Denning, C. B., \& Jamison, K. R. (2012). Communication skill building in young children with and without disabilities in a preschool classroom. The Journal of Special Education, 46(2), 78-93. https://doi.org/10.1177/0022466910378044

Teixeira, R., Fernandes, S., \& Bernardes, G. (2016). A educação especial na rede pública de educação em uma cidade do centro-oeste brasileiro. Revista Lusófona de Educação, 33, 179-195.

Recebido em: 09/11/2020

Reformulado em: 05/02/2021

Aprovado em: 06/02/2021 
CARVALHO, A.G.C. \& SCHMIDT, A. 